\title{
JVR: A Quality Journal Making the Most of the Net
}

For the past 10 years it has been my privilege to serve as Main Editor for the Journal of Vascular Research (JVR), first with Dr. Gary Owens, and now with Drs. Gerry Meininger and Ulrich Pohl as co-editors. Our aim has been that JVR should be broad in its coverage of vascular science, but selective in publishing only articles which met the criteria of 'scentific excellence and novelty'. It has been our belief that, despite the frustrations such a policy can cause for potential authors, in the long run it will be beneficial for the scientific community in general. This policy has been strongly supported by our Editorial Board and other reviewers, with the insistence that our criteria are adhered to. Indeed, the policy appears to have been successful, resulting in a steady increase in the Impact Factor which now stands at 3.6, a value which compares most favorably with other journals in our field.

With the advent of the Internet, traditional journals are facing new, but exciting, times. Word processors, E-Mail and the web allow many aspects of the publishing process to be performed more quickly as well as cheaply. However, in the Editors' view, the aim for speed at minimal cost must not override the need for full review, careful editing, and readable layout, all of which take time. To take advantage of the new possibilities, but at the same time preserve the traditional values, the Editors together with the publishers have agreed that we should use the electronic media for submission, review and publishing of papers to as great an extent as possible. The details of the new procedure are given below. By this means it is hoped that publication can be more rapid, without loss of quality. From acceptance it is anticipated that the paper can be on the Net within 2 months, and in printed form in the following number of the journal.
The other innovation, the JVR Internet Discussion Forum (http://www.karger.ch/journals/jvr/jvr_df.htm), will continue to promote one article per number where open discussion is possible prior to paper publication.

The Editors hope that JVR's readers, authors and reviewers will find these changes useful, to the extent that the publication process can be quicker and more convenient. However, our overall aim is unchanged. JVR must remain a quality journal.

Michael Mulvany Main Editor

\section{Procedure for Electronic Submission and Publishing}

- Manuscripts submitted to either the Aarhus or College Station offices should be sent as a single Word file (PC version) including the figures which must be placed at the end on separate pages, one figure per page. To avoid confusion, other formats will not be accepted. The manuscript may be mailed (jvr@farm.au.dk or gam@tamu.edu) as an attached file or by post on a diskette. In either case, two printed copies should also be submitted by post.

- Manuscripts will be sent to reviewers by E-Mail as attached files or by courier, at the reviewer's convenience.

- Responses from reviewers will be by E-Mail or fax, also at the reviewer's convenience.

- Primary correspondence with authors will remain by fax, but supplemented by E-Mail if needed.

- Final versions of manuscripts for publication will be requested to be submitted on disk as Word files for the text and as PowerPoint files for the figures, together with a printed copy.

Submission of printed material only will still be accepted and the current procedures will be followed. Full details are given in the Guidelines for Authors.

\begin{tabular}{ll}
\hline KARGER & ( ) 2001 S. Karger AG, Basel \\
Fax +4161306 1234 & \\
$\begin{array}{l}\text { E-Mail karger@karger.ch } \\
\text { www.karger.com }\end{array}$ & $\begin{array}{l}\text { Accessible online at: } \\
\text { www.karger.com/journals/jvr }\end{array}$
\end{tabular}

